\title{
HVMANITAS
}

A conciliação dialética como afirmação do divino na Antígona de Sófocles

Autor(es): $\quad$ Toledo, Daniel da Silva

Publicado por: Imprensa da Universidade de Coimbra

URL

persistente:

URI:http://hdl.handle.net/10316.2/44774

DOI:

DOI:https://doi.org/10.14195/2183-1718_72_1

Accessed : $\quad$ 26-Apr-2023 12:13:32

A navegação consulta e descarregamento dos títulos inseridos nas Bibliotecas Digitais UC Digitalis, UC Pombalina e UC Impactum, pressupõem a aceitação plena e sem reservas dos Termos e Condições de Uso destas Bibliotecas Digitais, disponíveis em https://digitalis.uc.pt/pt-pt/termos.

Conforme exposto nos referidos Termos e Condições de Uso, o descarregamento de títulos de acesso restrito requer uma licença válida de autorização devendo o utilizador aceder ao(s) documento(s) a partir de um endereço de IP da instituição detentora da supramencionada licença.

Ao utilizador é apenas permitido o descarregamento para uso pessoal, pelo que o emprego do(s) título(s) descarregado(s) para outro fim, designadamente comercial, carece de autorização do respetivo autor ou editor da obra.

Na medida em que todas as obras da UC Digitalis se encontram protegidas pelo Código do Direito de Autor e Direitos Conexos e demais legislação aplicável, toda a cópia, parcial ou total, deste documento, nos casos em que é legalmente admitida, deverá conter ou fazer-se acompanhar por este aviso. 


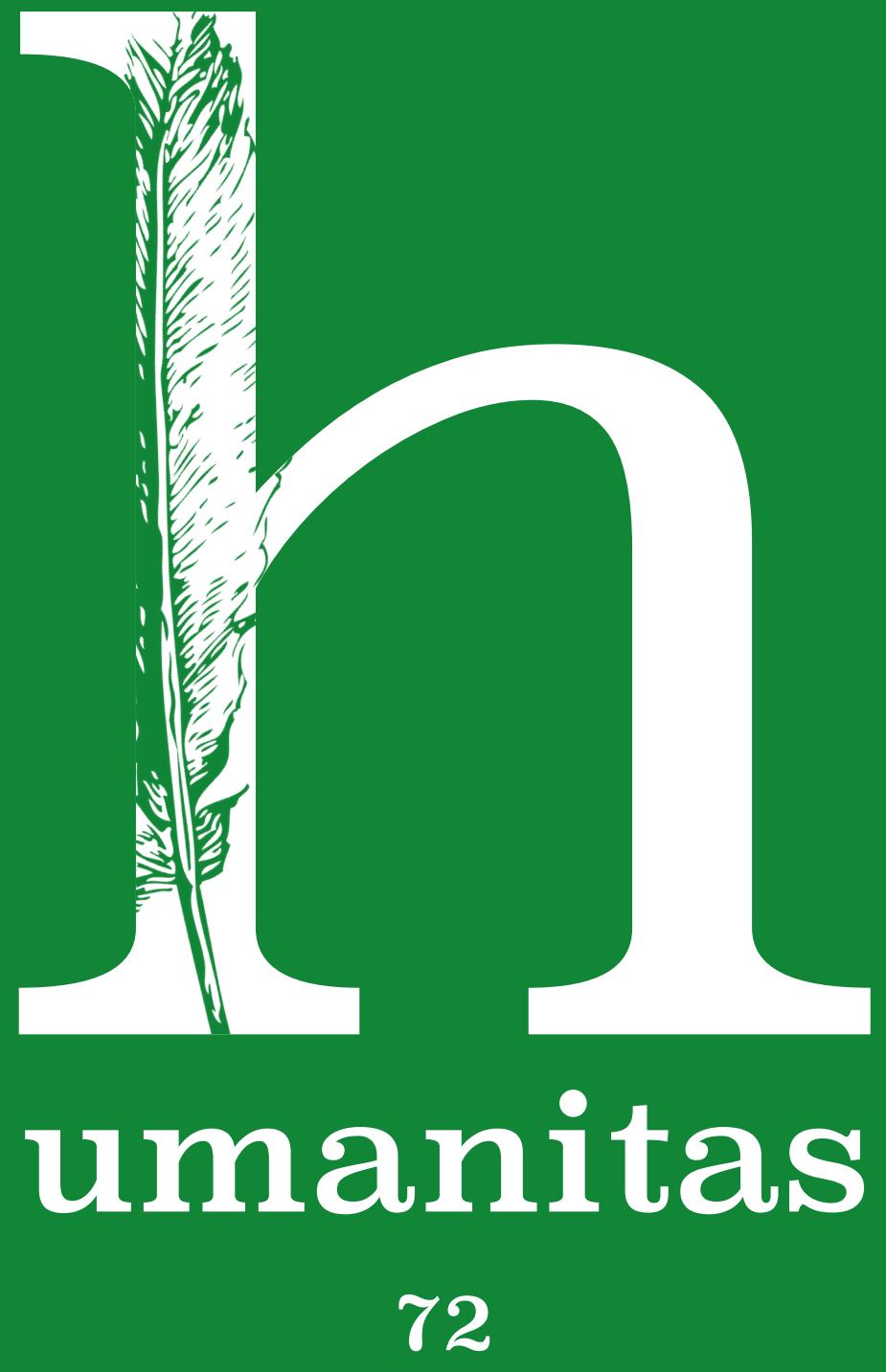

Imprensa da Universidade de Coimbra

Coimbra University Press 


\title{
A CONCILIAÇão dialétiCa COMO AFIRMaÇÃo do diVino NA ANTÍGona de Sófocles
}

\section{The dialectical CONCILIATION AS AFFIRMATION OF THE DIVINE \\ in the Sophocles' Antigone}

\author{
Daniel da Silva Toledo \\ dasilvatoledo@yahoo.com.br \\ Departamento de Filosofia da Universidade Federal de Juiz de Fora -UFJF(Brasil) \\ https://orcid.org/0000-0002-2502-7416
}

Artigo submetido a 01-02-2017 e aprovado a 15-12-2017

\section{Resumo}

Tendo como objeto de análise a tragédia Antígona, de Sófocles, este artigo partirá do pressuposto de que a relação de tensão representada pelo conflito entre Antígona e Creonte serve de plano afirmativo para uma instância que se superpõe a esta tensão: a da disposição divina. Tal afirmação, todavia, mostrar-se-á de uma maneira muito peculiar e por meio de uma característica marcante do poeta Sófocles, a saber, através do próprio distanciamento dos deuses acerca da tensão em questão. A partir disto, buscaremos oferecer, por fim, uma perspectiva antitética ao postulado tradicional de que Antígona seria essencialmente um drama de dissolução.

Palavras-chave: Antígona; Sófocles; afirmação dialética do divino; afastamento dos deuses; conciliação/dissolução.

\section{Abstract}

Taking the Sophocles' tragedy Antigone as object of analysis, this study will start from the presupposition that the relation of tension represented by the conflict between Antigone and Creon serves as an affirmative plane for an instance that superimposes to this tension: that one of the divine disposition. This statement, however, will be shown in a very peculiar way and by a striking characteristic of 
the poet Sophocles, through the own detachment of the gods about the tension in question. Finally, we will look for an antithetical perspective to the traditional postulate that Antigone would be essentially a dissolution drama.

Keywords: Antigone; Sophocles; Dialectical affirmation of the divine; Detachment of the gods; conciliation/dissolution.

A Antígona, de Sófocles, é considerada por parte significativa de seus intérpretes como uma tragédia de "dissolução". Partiremos aqui dessa referência para, ao fim, nos opormos à mesma. Não temos, com isso, a presunção de impor uma intepretação unívoca a uma obra poética de ampla complexidade ${ }^{2}$. Aquilo que pretenderemos de maneira conclusiva é apenas oferecer uma alternativa de leitura a uma determinada chave de compreensão já consolidada entre diversos especialistas que se debruçaram sobre a peça.

Basicamente, a referida caracterização de Antígona como drama de dissolução se dá em virtude do fato de sua heroína protagonista ser derradeiramente levada a sucumbir desamparada por qualquer assistência divina pela qual clama ao longo do drama, mesmo acreditando estar respaldada pelas leis sagradas. Como ordem de fundo dessa fratura, teríamos então uma clara dissensão entre os desígnios humano e divino.

Do forte teor da relação de tensão entre as resoluções humanas e a destinação imposta pelos deuses, tende-se a estabelecer uma espécie de dupla clivagem delimitativa neste drama sofocliano, primeiramente, através de um plano de ação conflitivo constituído pela interação de oposição que separa Antígona e Creonte ${ }^{3}$; e também por meio de outra espécie de hiato de sentido aberto pelo distanciamento dos deuses acerca do campo de ações telúricas que se desdobram desprendidas de qualquer tipo de intervenção divina em sentido direto ${ }^{4}$.

1 Beistegui/Sparks 2000: 21.

2 “Antígona é uma peça singularmente difícil de ser compreendida". Winnington-Ingram 1980: 117. A mesma opinião tem Mark Griffith, em Sophocles 1999: 25-26, 33, 34.

"Há duas tragédias se desdobrando simultaneamente: a tragédia de Creonte e a tragédia de Antígona". Winnington-Ingram 1980: 147.

4 Contrariamente a praticamente toda a produção clássica do gênero trágico remanescente (salvo raríssimas e relativas exceções), aqui "a divisão entre as leis divina e humana não assume a forma de uma confrontação direta entre homens e deuses". Steiner 1984: 31. Não obstante, "se a motivação dos poderes divinos permanece imperfeitamente 
Entendemos que este postulado da recusa do divino em se manifestar explicitamente fomenta aquela condição de confrontação entre as personagens humanas na medida em que dá margens para reapropriações de sentidos que, ao serem projetadas como mais elevadas através de idealizações singularizadas, não somente tornam-se conflitantes entre si, como também, de maneira ainda mais grave, se perfazem como redutivas da própria dimensão transcendente do mistério inacessível reportada à reserva da deidade. É esta redução que apresentaremos aqui como a hybris a ser punida pelos deuses ausentes como forma de conciliação do poder divino com a destinação final dos mortais.

\section{II}

O caráter determinante e impositivo da ausência da divindade na Antígona já se revela tão logo percebamos que as tentativas de reagir ao referido distanciamento entre deuses e mortais, apresentadas ao longo do drama, só se sustentam através de aproximações indiretas, como aquela abordagem que, por exemplo, nos indica que, segundo o horizonte de sentido da época de Sófocles, "o Estado está sob o cuidado dos deuses e um insulto ao Estado é um insulto aos deuses"

Por estar alicerçada na tradição, é evidente que essa crença realmente consolida-se como vigente em meio ao arcaico horizonte cultural grego. Todavia, o que se apresenta como excessivo em relação a essa ilação é a apropriação que da mesma é feita por um dos agentes do drama: "Ele [Creonte] acredita nos deuses, mas os identifica com o interesse do Estado e, em última análise, o Estado consigo próprio, com a sua ambição e poder"’.

indefinida, a culpabilidade humana é fortemente indicada". Winnington-Ingram 1980: 172. Segundo autora portuguesa, este preceito pode ser recolhido em um plano mais geral: "De qualquer modo, se os deuses recuam, neste trágico, para um plano longínquo, os seus desígnios já não são inequívocos ao ponto de transformarem as transgressões humanas em processo trágico de culpa e castigo ou desencadearem um conflito de princípios em que o Homem é, simultaneamente, culpado e agente punidor"! Fialho 1992: 15. Obs.: quanto à questão da culpa, no caso de Antígona, apesar de "nada intrínseco ao seu caráter ser predeterminante para a sua fortuna" (Steiner 1984:59), sabemos haver a maldição de sua casa! Cf. Steiner 1984: 63.

5 Kirkwood 1994: 121.

6 Winnington-Ingram 1980: 148. Consequentemente, e à primeira vista, "é um homem de princípios, que parece reto. Mas tem a visão limitada daqueles que, subindo ao poder, pensam subir ao pináculo de si mesmos”! Bonnard 1984: 208. 
Essa forma de ligação torna essa relação relativamente tênue. Estabelece-se uma modalidade de vínculo que, pela falta de consistência provocada pela ausência do que seria seu principal polo aglutinador e regulativo, no caso, a presença determinante da deidade, abre uma margem de ação na qual os agentes constitutivos do outro polo, a saber, as personagens humanas, encontrarão espaço para inserir certas práticas idiossincráticas.

No caso aduzido, por exemplo, podemos observar que, ao se valer do argumento citado para justificar seus interesses de estadista, perfaz-se como imputável a Creonte uma postura de conveniência inescrupulosa, que o permite não ter de reconhecer que, em contrapartida, comete também "um crime contra o mandamento divino que ordena honrar os mortos" Entrementes, este mandamento, neste momento, encontra-se já muito mais reportado a uma espécie de tradição "canônica" (dito com o perdão do anacronismo!) do que a um desígnio claramente divino, naquele sentido teatral de ser remetido in voce a alguma deidade que se faz presente por meio de sua intervenção direta. Dessa forma, no espaço de crise aberto pela ausência de confirmação definitiva do que seria a vontade dos deuses em última instância, Creonte encontra margem para projetar seus anseios pessoais como sendo de uma vontade superior ${ }^{8}$. Recurso a ser empregado também por sua oponente?

Ainda da parte de Creonte, aquela recursividade argumentativa ganhará mais amplitude de defesa através do postulado geral de que a pólis também representa o espaço de incidência do divino e que Polinices tentara invadir

7 Lesky 2006: 153.

8 Cf. Steiner 1984: 94. Obs.: aqui não nos importa tanto se a verdadeira razão de fundo para este interesse repousa, com Hegel, na defesa do Estado ou, com Goethe, no ódio pessoal a Polinices! Cf. Steiner 1984: 50.

9 Em se recorrendo ao Romantismo, poder-se-ia aqui ressalvar que "os deuses nos falam somente através de nossos corações”! Steiner 1984: 47. Não obstante, entendemos ser importante e necessário apresentar um cuidado acerca do risco de certa inversão de sentido que, apesar de aparentemente sutil, pode ser significativamente sintomática para o propósito de situar a verdadeira posição ou estado de espírito da heroína, pois a nós parece que Antígona não defendia o funeral com a finalidade de afirmar as leis divinas, mas sim se valia destas para tentar alcançar aquele: "É ao amor do corpo fraterno que Antígona vai buscar toda a força de revolta que a levanta contra a vontade dos homens, toda a força de obediência que inteiramente a submete a Deus". Bonnard 1984: 220. E quem sabe se talvez não seja justamente por essa espécie de transposição de princípios que "nada é dito por Tirésias ou qualquer outro que mostre que os deuses tenham aprovado as suas ações"?! Mark Griffith. In: Sophocles 1999: 32. 
a cidade de Tebas. Objeção que atinge ainda maior força persuasiva por meio do seguinte argumento inicialmente direcionado contra o coro:

É intolerável o que dizes, Que por este corpo a providência dos deuses

Tenha algum cuidado. Acaso eles enterrariam a ele, Concedendo-o altas honras como se fosse seu benfeitor, Aquele que veio para deitar fogo em seus santuários colunados, Para profanar suas oferendas e suas terras, E todos os seus costumes habituais? Viste Os deuses aprovando homens de más ações?

Não é assim! $!^{10}$

O que se revela através desta linha de argumentação é que este artifício retórico do tirano é aplicado sob a intenção de colocar o Estado em paridade estatutária ao $\mathrm{Olimpo}^{11}$. Isso de tal maneira que a resolução de Antígona, confrontada por esta ótica, mostrar-se-á como uma afronta a um sentido estabelecido pelo tirano como de ordem divina superior àquele crível por Antígona também como tal.

Também Antígona acredita poder se valer piamente da crença de que o seu interesse se coaduna com a vontade divina. Como observa Albert Zink, na medida em que o sepultamento é um direito sagrado, pode-se dizer que, de sua parte, ela "defende o direito dos deuses"; ao passo que, em contrapartida que cabe ao tirano em sua luta pela preservação do poder político, "Creonte e o coro não reconhecem o direito incondicional, elementar, da physis humana, que os deuses querem ver afirmada" 12 . Devemos observar, todavia, que, também no caso da postura de Antígona, a mesma é passível de ser contextualizada através de um horizonte em que o pretenso respaldo divino é muito mais reportável aos preceitos da tradição religiosa grega

10 Sophocles 2001: 9 [vs. 316-324]. Na linha de Hegel, argumenta-se que Creonte mostrar-se-ia justo pela recusa em honrar o invasor da cidade. Steiner 1984: 37, 41. Todavia, se considerarmos o antecedente da narrativa mítica, apresentado por Ésquilo em Sete contra Tebas e por Eurípides em As Fenícias, há de se aduzir o fato de que, para seu interesse próprio, o tirano desconsidera que Polinice somente assim o intentou em razão da recusa de seu irmão, também sobrinho de Creonte, em transmitir-lhe o direito ao trono, conforme previamente acordado entre ambos! Cf. Toledo 2015: 295, 432.

11 "Mas o próprio Creonte dirige-se repetidamente a Zeus e aos deuses da sua cidade"! Mark Griffith, in: Sophocles 1999: 47.

12 In Sophokles 2005: 135. 
do que a qualquer sentença declaradamente favorável a ela por parte de alguma divindade figurada como tal. De toda forma, ainda sob a perspectiva da heroína, fato é que, diante da obstinação de Antígona em remeter sua resolução ao direito divino, Creonte, ao ter de reafirmar o poder político, acaba sobrelevando o Estado à forma não só como Antígona concebe o que seria a disposição divina, mas, ainda mais, a um horizonte de sentido que tradicionalmente confere sustentação de ordem transcendental aos valores relativos às relações humanas.

Até este momento, contudo, a hybris de Creonte era apenas - na falta de termo melhor! - "indireta", uma vez que atentava "somente" contra um direito sagrado, o de dar sepultura aos mortos ${ }^{13}$. Direcionada mais especificamente contra Antígona, sua desmedida se restringia a uma tensão radicada mais no plano telúrico ${ }^{14}$. Mas na medida em que a sua oponente reforça cada vez mais a ligação de seu desejo com as leis divinas, o tirano acaba por se deixar envolver por esta ilação e com isto se excede investindo nominalmente contra os deuses. Dessa forma, ele, ao fim, despe-se mesmo daquela aparência de escrúpulo na medida em que se destitui de qualquer pudor no seu trato direto com o simbolismo divino, incorrendo assim na hybris essencialmente trágica determinada pela afronta aos deuses:

Assim deixe-o invocar

A Zeus, o senhor da parentela. Se eu dou as costas

Para os meus, propicio coisas desagradáveis e desprovidas de ordem [...]

Nem se as águias, aves de Zeus, carregarem

Seus pedaços de carniça ao trono do supremo,

Nem mesmo temendo essa polução terrível,

Eu consentirei este sepultamento ${ }^{15}$.

Todavia, a transgressão desse limite não fará com que os deuses passem a estar ao lado de Antígona. Ao se voltar explicitamente contra os deuses, a derrocada final de Creonte confirmará a imposição de uma ordem

13 É o que percebe também Mark Griffith, em Sophocles 1999: 47.

14 Arrolando algumas indicações de autores e apontamentos de evidências textuais, quem contesta a aceitação imediata de que na Grécia Arcaica a recusa de sepultamento seria um sacrilégio "inabalável ou evidente por si mesmo", principalmente no caso de "traidores" do Estado, é Mark Griffith, em Sophocles 1999: 29-32.

15 Sophocles 2001: 20, 31 [vs. 750-752, 1189-1192]. 
superior que se legitima muito mais por si mesma do que pela restauração do direito reivindicado pela heroína, uma vez que esta também sucumbirá, sem sequer conseguir dar sepultura ao irmão.

Vemos agora que aquele Creonte que dantes aparentava pretender elevar o Estado à condição divina se revela como um agente político que, na verdade, crê poder tornar os deuses subordinados aos interesses estatais. Não é que somente então o papel da deidade concebido pelo tirano em sua relação com o Estado decai, mas finalmente se evidencia neste momento aquilo que já fora seu estatuto tácito inicial.

Uma vez desnudados os caracteres de fundo dos protagonistas, o conflito de consciências que serve de moto ao drama pode agora ser muito bem descrito através da seguinte confrontação: "Creonte crê nos deuses, mas os seus deuses vergam-se estritamente a esta ordem cujo pólo é cívico: estão, como os homens, comprometidos no serviço do Estado. Creonte está fechado a deuses que não tenham por primeira função assegurar a estabilidade do Estado e por consequência punir os rebeldes. Quando Tirésias lhe faz entender a linguagem dos deuses, que são outra coisa que não isto, blasfema. Deuses e sacerdotes são funcionários, ou não o são. Os deuses estão nacionalizados (como tantos outros na história). Defendem fronteiras. Honram o soldado que cai ao defender as mesmas fronteiras que eles. Castigam quem quer que, fora ou dentro - Polinices ou Antígona -, se recuse a reconhecer a ordem estabelecida e garantida por eles, a autoridade suprema do Estado. [...] Frente a este mundo de Creonte, em que tudo está no Estado, eis, mais vasto, o cosmo de Antígona. Ao passo que Creonte submete o homem e os deuses, e todo o valor espiritual, à ordem política $\mathrm{e}$ nacional, Antígona, sem negar os direitos do Estado, limita-os. Os decretos de um homem, diz ela, desse homem que fala em nome do Estado, não podem prevalecer sobre as leis eternas de que a consciência é depositária. Antígona não contesta a lei dos homens, mas afirma a existência duma realidade superior" ${ }^{\prime \prime}$.

Entrementes, por mais que com isso pareça que ao cabo um determinado ideal se sobreleve, e ainda que à primeira vista tenhamos claramente uma relação de oposição, defendemos a tese de que, se observarmos bem, pode-

16 Bonnard 1984: 225. “A 'lei' (nomos) não é uma ordem dada aos homens, mas um princípio que rege a vida humana”. Winnington-Ingram 1980: 169. 
remos entrever que em ambos os polos dessa tensão opera implicitamente determinadas reduções do estatuto divino em seu caráter de transcendência ${ }^{17}$.

\section{III}

Creonte, como já ressaltado, torna os deuses, através de sua espécie de "crença cívica", subordinados aos interesses do Estado, do qual ele é representante maior e deve, a partir de seus próprios princípios de estadista, projetar uma concepção do divino configurada estritamente como pilar da polis. Esta projeção está tão arraigada em seu âmago que se revela reativa mesmo à voz do profeta que segundo a tradição religiosa grega seria a representação mais direta possível dos desígnios dos deuses quando estes não se expressam "por si próprios".

De sua parte, Antígona crê a si mesma como fiel depositária de um determinado valor espiritual apropriado conscientemente através da finalidade de que seu mais íntimo desejo passional encontre respaldo numa referência, por assim, dizer, indireta aos deuses.

A partir dessa chave interpretativa acerca das posições das personagens, nosso ponto de vista a ser explicitado neste momento consiste em afirmar que a relação, à primeira vista antagônica, entre o tirano e a heroína não nos serve, no fundo, como a constituição essencial entre o tético e o antitético no processo dialético a ser depreendido do drama, mas que em essência constitui tão somente, através da reunião dos opostos, uma primeira premissa a servir de causa explicativa para a ausência do divino que se nos desvelará como determinante para a anulação da existência de ambas as consciências redutivas ${ }^{18}$. A partir disso, queremos

17 Segundo compreende também Mark Griffith, "o texto mostra, para além das dúvidas razoáveis, que ambos, Creonte e Antígona, são, em última instância, parcialmente (mesmo que não igualitariamente) responsáveis pela tragédia”! In: Sophocles 1999: 29. Do contrário, isto é, se adotássemos a dicotomia puritana que reserva a um a exclusividade da má conduta terrena e à outra apenas o pietismo devocional, sujeitaríamos o drama a ser reduzido a uma mera lição moral! Cf. Sophocles 1999: 28, 46-47.

18 Tendo em consideração que, "Fatum, na tragédia grega, é um poder invisível, inacessível às forças naturais, e imperativo mesmo sobre os deuses" (Steiner 1984: 2-3), poder-se-ia lançar a desconfiança se o recolhimento divino não traduziria, antes, certa inoperância dos deuses. Todavia, entendemos que essa desconfiança deve ser desfeita tão logo se considere que esta destinação, em geral, também tem, ao cabo, seu ditame repousando no seio divino e que, por isso, podia, ocasionalmente, ser reconfigurada pelos deuses mediante ajustes de forças entre os 
apontar que a síntese final a ser operada através dessa forma de relação aqui aventada deve corroborar a tese de tratar-se Antígona de um drama de conciliação mais elevada operada através da dissolução interna dos elementos mediadores.

A orientação final para a afirmação do poder divino começa a ganhar força quando Creonte só se mostra disposto a retroceder, tarde demais, diante dos vaticínios do profeta Tirésias. Neste ponto, devemos observar que um dos poucos juízos da peça que podem ser reportados aos deuses, ainda que indiretamente, faz alusão à condenação do ato de Creonte. Todavia, entendemos que a forma peculiar através da qual o desígnio divino se impõe da maneira mais vigorosa não se encontra em qualquer alusão explícita aos deuses, mas antes justamente na recusa destes em se manifestar por meio de qualquer intervenção diretiva. Lançando mão deste recurso de manter os deuses distanciados como forma velada de determinação do drama, a engenhosidade artística de Sófocles deixa implícita uma interação mais ampla encoberta por todas aquelas relações de tensão entre as personagens humanas: "Os eventos com que Creonte depara e que se opõem à sua vontade também são, sem sombra de dúvida, resultado da atividade humana; todavia, o modo com que isso cruza seu caminho não pertence mais à ação como ação humana - mesmo que Antígona seja a causa consciente de todo o restante -, mas é parte da relação divina, a qual atua no que é humano por meio da ação. Para causar ainda mais confusão à sagacidade humana e para enredar ainda mais o poderoso no jogo é violentado o próprio sentido da relação humana"19.

O que se desvela através dessa perspectiva é o postulado de que os deuses permitem, de maneira tácita, que as ações desdobradas não somente não se orientem para a finalidade de resolver ou dissolver o conflito pendendo para qualquer um dos lados envolvidos, mas que também, sobretudo, o desfecho do drama fomente a reafirmação do poder divino para além do campo de ação dos mortais, independente de quão mais as reivindicações

mesmos. Além disso, diferentemente de praticamente todas as demais peças trágicas supérstites, neste drama os deuses não se deixam mover sequer pela necessidade das personagens de que seja oferecida uma resposta do alto aos seus anseios. A nós, essa posição inamovível, em contraste com um universo de sentido todo permeado pela influência direta de ações divinas e, mais especificamente, indiferente a toda passionalidade apelativa que confere força à economia dramática da obra em questão, é exponencialmente demonstrativa de uma singular forma de exercício de poder.

19 Reinhardt 2007: 91. 
destes possam se aproximar de qualquer referencial projetado à vontade divina a partir de suas próprias limitações de perspectivas. E para isso, tudo que os deuses precisam fazer é simplesmente se recusar a intervir, indiferentes aos recorrentes clamores que despontam em meio a praticamente toda a peça ${ }^{20}$.

Tanto Creonte quanto Antígona, cada qual à sua maneira, sucumbem justamente por acreditar terem os deuses aos seus lados quando, na verdade, ambos não os tinham. No caso ainda mais latente de Antígona, em se considerando sua conformidade às leis sagradas, poder-se-á, de fato, dizer que, assim, "obedecendo à lei de Zeus, ela é destruída por ele"21. A derrocada da heroína não é determinada por nenhuma sentença divina anunciada como tal, mas tão somente pela recusa do deus em interceder por ela. Entendemos ser neste sentido fundamental que "o deus se faz presente na figura da morte" 22 .

A recusa do divino revela também que o fim de Antígona se faz necessário não somente para consumar o trágico, mas antes como antítese para a hybris de Creonte, que o levará à ruína. Logo, por mais que o tirano tenha procurado colocar a necessidade da ordem política acima de todas as circunstâncias, inclusive acima da tradição religiosa, justamente através disso, para atender aos propósitos do poeta, ele teve de, no fim, ceder através de sua própria catástrofe. Até que finalmente, aniquilado, se veja "forçado a abjurar cada um de seus juramentos" ${ }^{23}$.

Creonte cede, mas ainda assim seu destino é trágico, como também o é o de Antígona, pois ambos, ainda que por motivos diferentes e através de maneiras distintas, sucumbem através da deposição divina. Creonte é condenado por sua hybris face aos deuses, mas Antígona também é condenada na medida em que não pode comover os deuses a flexionar seu destino que está visceralmente enredado no do tirano.

A resolução de Antígona em caminhar para a morte, na medida em que desencadeia aquela hybris de Creonte que será punida pelos deuses, obedece à disposição divina reforçada não somente como inapreensível pela vontade dos mortais, mas também projetada como superior às próprias leis tradicionalmente postuladas como de ordem sagrada. Assim, se da confrontação entre duas resoluções humanas que soçobram o que se afirma

20 Quem apresenta uma recolha das significativas referências feitas aos deuses é Winnington-Ingram 1980: 108-116.

$21 \quad$ Winnington-Ingram 1980: 172.

22 Machado 2006: 163.

23 Rudnytsky 2002: 299. 
é justamente o plano que as excede, é como se com isso tivéssemos uma espécie de "conciliação final" que, através de uma relação de subordinação e de superioridade,

Depende do juramento dos deuses nas alturas ${ }^{24}$.

Por sobre a vontade humana, prevaleceria para os próprios humanos uma destinação final em consonância com a disposição divina enquanto inapreensível e irrefreável por parte daqueles que são subjugados por forças que não podem ser coagidas e nem quebrantadas por meio algum. Isso de tal forma que todas as dissonâncias despontadas no plano telúrico revelar-se-iam conformes a uma regência de sentido que se lhe impõe como determinação de fundo.

Ao aventarmos essa chave interpretativa, não temos por pretensão dissolver o caráter profundamente trágico do drama, que se mantém inegavelmente, mas tão somente indicar que o sentido de fundo da peça pode ser compreendido como orientado para a tentativa em mostrar que até as mais ferrenhas das resoluções humanas encontram seus limites ao se chocarem justamente contra as determinações que se recusam à apreensão dos mortais. Logo, por mais que os deuses não sejam levados ao palco nessa obra, não será forçoso inferir que, através da consumação da resolução pessoal de Antígona em ir ao encontro da morte, "Sófocles conclui com a superioridade dos atos que se acordam com a vontade dos deuses; conclui que nada pode vencer a força dos imortais e que o destino humano passa necessariamente por suas leis" 25 .

Contra essa perspectiva, poder-se-ia insistir com a objeção de tratar-se de um drama de dissolução, uma vez que Antígona tem seu fim sustentado pelo desamparo divino. E, de fato, como observa Françoise Dastur, diante de seus apelos mais comoventes Zeus permanece como aquele "que não a reconhece", mas que ainda assim permanece sendo também "aquele que Antígona reclama" ${ }^{26}$. Logo, se observarmos bem, veremos que o abandono

24 Sophocles 2001: 11 [v. 406].

25 Bignotto 1998: 71. Por tudo isso, a nós não parece tão problemático quanto o é para Kitto reconhecer que aqui pode ser revelada uma certa "confissão de fé religiosa" do poeta! Kitto 1972: 237. Posição discordante a de Kitto também é a de Mark Griffith em Sophocles 1999: 46. Obs.: para saber mais sobre como depreendemos a visão religiosa de Sófocles através do papel dos deuses em suas peças como um todo, ver Toledo 2015: 309-383.

26 In Hölderlin 1994: 196. 
se consuma apenas por parte do deus. E ainda assim ele permanece como referência central para o apelo derradeiro da heroína ${ }^{27}$. Diante disto, não entendemos como um estudioso da importância de Kitto, por exemplo, pode inferir que Antígona "não tem confiança nem mesmo nos deuses" ${ }^{28}$. Como isto seria possível quando ela declara veementemente se apoiar nas "leis não escritas" mesmo quando os deuses se recusam a ampará-la? Frente a essa interpretação, sentimo-nos minimamente à vontade para afirmar que este importante estudioso não captou o espírito da referida tragédia! Até por afirmar que "Antígona sentia-se sem coragem" 29 . Como sem coragem, se caminha irresoluta até à morte mesmo sentindo-se desamparada pelos deuses? Parece-nos evidente que ela se fia profundamente nos deuses mesmo diante da ausência dos mesmos quando ela, ameaçada por Creonte -

Tu então te atreveste a desobedecer estas leis?

-, responde com a célebre objeção:

Sim, as quais não foi Zeus quem concebeu,

Nem a Justiça, habitando com os deuses inferos,

Quem traçou estas leis para todos os filhos dos homens;

Nem eu considerei este edito forte o bastante,

Vindo de um homem mortal, para reduzir a nada

As leis não-grafadas do deus que não conhece mudança.

Elas não são de hoje e nem de ontem,

Mas vivem para sempre. E homem algum pode fixar

Quando elas pela primeira vez surgiram para a existência. Não é por medo

Da resolução de qualquer homem que estou disposta

Diante dos deuses a sofrer a punição

Por estar pecando contra eles. Que eu devo morrer,

Eu sei (como eu não deveria?), ainda que este decreto

Nada tenha me falado. E, se antes do meu tempo

Eu devo morrer, considero isto um ganho;

Para aquele que vive, como eu, em muitas aflições,

Como a morte não deveria lhe trazer ganho?

E assim, para mim, suportar essa tua condenação

Nada tem de doloroso. Mas se eu tenho que deixar

27 Cf. Winnington-Ingram 1980: 165.

28 Kitto 1972: 239.

29 Kitto 1972: 333. 
O filho de minha mãe insepulto nessa terra,

Eu teria dor. Mas como as coisas estão,

Eu nada sofro. E se devo eu lhe parecer

Como se tivesse praticado uma ação insensata, é simplesmente porque

Eu sofro acusação de insensatez por parte de um insensato ${ }^{30}$.

Toda essa declamação evidencia que Antígona perfaz-se como vinculada àquela instância que se lhe impõe como superiora justamente por se mostrar distanciada de seus anseios ${ }^{31}$. A formulação de sua condição trágica se torna impositiva por meio de uma ligação mediada justamente pela distensão de sentido entre os elementos em relação. Ela abisma-se assim no próprio hiato de significação para os seus atos aberto pela divindade que recusa a se conformar aos seus anseios singulares ${ }^{32}$. Ainda assim, não devemos perder de vista que a inquebrantável obstinação pessoal da heroína em sustentar até o fim este vínculo inconsumável deve deixar claro também para nós que ela se ampara sempre naquilo que acredita ser a justiça divina, mesmo nunca obtendo garantia alguma acerca da mesma. Logo, não nos parece acertada a tese de que Antígona representaria uma renúncia aos deuses, ainda que o drama seja essencialmente marcado pela renúncia dos deuses. Tanto assim é que, se nos ativermos à palavra do poeta, podemos perceber que no único momento em que Antígona declama sentir-se desamparada pelos deuses, segue ao lamento a resignação confiante justamente na justiça divina:

Se atos como este os deuses celestiais aprovam,

Nós, instruídos pelo sofrimento, seremos os próprios a terem pecado;

Mas se eles pecam [olhando para Creonte], eu rogo para que o seu sofrimento não Seja um mal pior do que os erros que me imputam ${ }^{33}$.

30 Sophocles 2001: 13-14 [vs. 492-516].

31 É, inclusive, em virtude deste distanciamento supressivo de qualquer possibilidade de redenção da heroína que a conciliação pela dissolução que se aventa aqui deve ser compreendida como essencialmente distinta daquela apresentada no Coloneus, onde "a certeza de uma morte próxima [...] significa a rearmonização de Édipo simultaneamente com o mundo e com os deuses"! Fialho 1992: 17.

32 "Os deuses (predominantemente) parecem mais interessados na punição do que em recompensar ou confortar”! Mark Griffith, in: Sophocles 1999: 46. Segundo hipótese aventada por Karl Reinhardt, "ela não obtém as garantias dessa ordem do alto" justamente porque, no fundo, "Antígona não possui em si mesma o deus como força movente", de tal forma que, ao fim, se revelaria tão somente como "uma vítima a serviço dos deuses"! Reinhardt 2007: 94.

33 Sophocles 2001: 28 [vs. 1064-1067]. 
Todavia, como é sabido, o drama, de maneira magistral e ironicamente trágica, consuma-se com a imbricação dos padecimentos de ambos, em igual medida $^{34}$. E se em justa medida ou não, não nos parece mais alcançável dizer.

\section{Referências bibliográficas:}

Beistegui, M. / Sparks, S. (Eds.) (2000), Philosophy and Tragedy. London/New York: Routledge.

Bignotto, N. (1998), O tirano e a cidade. São Paulo: Discurso Editorial.

Bonnard, A. (1984), A civilização grega. São Paulo: Martins Fontes.

Fialho, M. (1992), Luz e trevas no teatro de Sófocles. Coimbra: Instituto Nacional de Investigação Científica.

Hölderlin, F. (1994), Reflexões. Seguidas de "Hölderlin, Tragédia e Modernidade", por Françoise Dastur. Rio de Janeiro: Relume-Dumará.

Kirkwood, G. (1994), A Study of Sophoclean Drama. New York: Cornell University Press.

Kitto, H. (1972), A tragédia grega. Coimbra: Arménio Amado.

Lesky, A. (2006), A tragédia grega. São Paulo: Perspectiva.

Machado, R. (2006), O nascimento do trágico. Rio de Janeiro: Jorge Zahar.

Reinhardt, K. (2007), Sófocles. Brasília: UnB.

Rudnytsky, P. (2002), Freud e Édipo. São Paulo: Perspectiva.

Sophocles (1999), Antigone. Edited by Mark Griffith. Cambridge: Cambridge University Press.

Sophocles (2001), Antigone. Translated by E. H. Plumptre. New York: P.F. Collier \& Son (The Harvard Classics, edited by Charles W. Eliot, vol. 8, Part 6, of 51).

Sophokles (2005), Antigone. Stuttgart: Reclam.

Steiner, G. (1984), Antígones. How the Antigone legend has endured in western literature, art, and thought. London: Yale University Press.

Toledo, Daniel (2015), O fundamento trágico da metafisica a partir da ontologia de Heidegger. A originária correlação histórico-existencial entre tragédia e niilismo. Saarbrücken: NEA.

Winnington-Ingram (1980), R. Sophocles. An Interpretation. Cambridge: Cambridge University Press.

34 “A 'polêmica' entre o Deus e o homem, o processo de colisão transcendental, pressupõe a morte ou, expressando de maneira mais rigorosa, a autodestruição do protagonista [...]. Somente assim, com tal morte, pode haver a restauração do equilíbrio". Steiner 1984: 76-77. 